\title{
Digitalization of Transport Services as a Way to Improve the Environmental Situation of Large Cities
}

\author{
Bardasova E.V. \\ Management Department \\ Kazan National Research Technological University \\ Kazan, Russia \\ eleonora.bardasova@yandex.ru
}

\author{
Utkina E.I. \\ Management Department \\ University of Management " TISBI" \\ Kazan, Russia \\ utochkamicra@mail.ru
}

\begin{abstract}
The Relevance of the study is due to the fact that the orderly movement of traffic flows, reducing downtime and congestion, due to the digitalization of transport services, will ensure their implementation on time and reduce the burden on the environment. The aim of the study is to develop an empirical model that links the results of flow detection and their evaluation by satellite intelligent systems to optimize motion. The research methods were analysis, comparison, identification of contradictions, synthesis based on the study of scientific information; observation of practical implementation of detection and optimization of transport flows; modeling of prospects for digitalization of this sphere. The novelty of this study is the theoretical justification of the possibilities of digitalization of transport services for dynamic traffic management, while improving the environmental situation in large cities. The proposed empirical model of digitalization of transport services sphere has practical value. it provides the possibility of integration of data from motion detectors and intelligent systems with subsequent modeling of flows and issuance of corrective actions.
\end{abstract}

Keywords-transport service; digitalization; detector; intelligent system; ecology.

\section{INTRODUCTION}

The sphere of transport services covers passenger, cargo and cargo-baggage transportation, including maintenance, repair of vehicles and related services [1], the prediction of the terms of which execution is possible only if there are data on the movement of traffic flows along the route of the unit of transport.

Megacities of the world and large cities of Russia are characterized by uniformity of the problems connected with an overabundance of vehicles and insufficiency of capacity of road networks. If it is impossible to foresee areas of excessive flow density and transport downtime, the probability of providing transport services on time decreases.

The possibilities of solutions for redevelopment and expansion of the road network, due to the construction of bypass, parallel, duplicate roads, multi-level overpasses and other construction measures to improve the throughput characteristics of the network, have not only financial but also territorial restrictions. Thus, the Central areas of large cities, which are often historical centers, are limited in structural changes.

A significant increase in the number of units of personal vehicles in large cities leads to significant traffic congestion and long downtime of all modes of transport, which prevents the systematic provision of transport services. In addition, areas of excessive traffic intensity, pockets of congestion and congestion of vehicles have an increased burden on the environment, which makes it relevant to study the possibilities of digital optimization of traffic.

\section{LITERATURE REVIEW}

Sustainable development of the economy of large cities, along with other factors, is associated with the effective organization of transport services. The population growth (including through migration), improve his well-being leads to an increase in units of private vehicles and growth in all types of freight and passenger traffic [2]. The congestion of the transport system of large cities creates obstacles for forecasting the timing of transport services.

The analysis of publications in the collections of Transportation Research Proceedings and Russian studies, reflecting the foreign experience of reducing the load on the sections of road networks, allows us to identify options for the organization of traffic in large cities of European and Asian countries.

Common for foreign countries and Russia is the use of both constructive measures for the construction of new roads, interchanges, above-ground and underground pedestrian communications, intercepting and traditional Parking, and regulatory measures-dynamically changing traffic lights depending on traffic, prohibitions of turns, oneway and reverse traffic, restrictions on entry into Central areas during peak hours.

At the same time, in overpopulated megacities of Asia (Seoul, Beijing, Tokyo), including in connection with the unfavorable environmental situation, economic measures of 
traffic regulation are widely used: payment for entry into Central areas, payment for traffic on high-speed and bypass highways, etc., to increase the accessibility of historical, industrial and business districts of large cities [3].

At the same time be aware that activities aimed at improving environmental performance of road transport system, such as the use of modern fuels and electric vehicles [4], the improved safety components of road surfaces, improvement of the composition and construction of tires, etc. [5] do not demonstrate adequate efficacy in high-density traffic flows and the non-working pieces of equipment in jams with the engine running.

The threat to the environment and the need to provide transport services on time [6] requires the development of measures to increase the capacity of congested roads and the rhythm of traffic. In large cities of Russia, the emergence of areas of difficult traffic and congestion can be associated with: territorial and financial constraints of the construction of new objects of the road network; redundancy of perpendicular intersections with insufficient ring connections; Parking problems; lack of programmable traffic lights; departures of unscrupulous drivers to the lanes of public transport and oncoming traffic [7,8].

The need to address issues of uninterrupted provision of transport services, ensuring traffic safety and reducing the environmental burden from the impact of transport on the environment requires the detection and management of flows. Determination of the composition and number of units of transport in the flow, the possibility of automated data accounting in a single system, the use of satellite intelligent transport systems [9] serve as the basis for innovative sustainable development of territories [10] and reduce the load on the environment.

In the practice of management of the sphere of transport services, computer programs and models for forecasting changes in the nature of traffic after constructive, regulatory and economic decisions are known. For example, it is possible to assess the potential for increasing capacity when introducing ring sections and radial directions of traffic, when closing or redirecting traffic depending on the periods of road load, as well as changes in the density of flows when introducing fees for entry to congested directions of traffic [11].

Flow control systems are also known, where the input information is various object detection data and motion characteristics. Detectors can be: special sensors on the vehicle; induction, infrared, radar, ultrasonic sensors in the roadway and above it; photo-video devices [12].

Perspective is not only control of observance of traffic rules with application of such variants of detection of a stream, but also the account of data on structure and density of streams in the uniform automated system, for development of operating influences on a stream. For example, traffic data received by the unified traffic control center will allow predicting the threat of obstructed traffic in advance and adjusting the operating time of traffic lights
[13] or information boards on options for changing traffic directions, before the formation of traffic jams.

The analysis of the content of Russian and foreign studies in the field of digitalization of transport services revealed the lack of model ideas about the potential of dynamically updated data accounting from various detectors and intelligent transport systems on the composition and movement of the flow and the development of corrective actions. Accordingly, it is necessary to empirically model the possibilities of traffic optimization for the provision of transport services in a given period and to reduce the environmental burden on the transport-saturated territories.

\section{RESEARCH METHODOLOGY}

The aim of the study is to develop an empirical model that links the results of flow detection and their evaluation by satellite intelligent systems to optimize motion.

Goal achievement was accompanied by the decision of the task of generalization of world experience of traffic optimization; theoretical substantiation of opportunities of the digitalization of the transportation sector for dynamic motion control with simultaneous improvement of ecological situation in large cities; development of models of digitalization sphere of transport services, providing data integration with motion detectors and intelligent systems, followed by modeling flows and results of corrective actions.

The research methods were analysis, comparison, identification of contradictions, synthesis of scientific statements based on the study of publications; observation of the practical implementation of detection and optimization of traffic flows; modeling of prospects for digitalization of this sphere.

The information base was the research published in the Transportation Research Proceedings for 2012-2019, scientific publications of Russian authors, programs of the Republic of Tatarstan on the development of transport services and the environment of the transport sector.

\section{RESULTS}

\section{A. environmental Impact of transport services}

According to the program of development of production forces of the Republic of Tatarstan until 2030 [14], the studied region is on the way of Federal routes of the West-East, West-South-East and North-West-South directions, the intersection of which forms the Kazan transport hub. The density of roads of the Republic is 1.6 times higher than the average in the Volga district.

Of all modes of transport, an increase is observed in the volume of road transport, which, in the innovative scenario will increase to 1.8 times by 2030 In development plans the necessity of construction of new roads in the interior appointments, bridges and external connections, bring in the proper condition of the sites of Federal highways, construction of toll roads, logistic centres and implementation of information systems of traffic control. 
At the same time, the need for environmental monitoring of the impact of the transport sector on the environment is noted. The unsatisfactory state of the environment of the Republic is characterized with the excess of pollution standards for air, soil and water resources, which, among other things, is associated with increased emissions from the functioning of the transport sector $[14,15]$.

It should be born in mind that harmful gaseous compounds and heavy metals entering the atmosphere and soil gradually migrate into the aquifers, polluting water resources. As harmful substances from vehicles can be identified - nitrogen and sulfur dioxides, sulfates, cadmium, lead, Nickel, copper, mercury, chromium, benzopyrenes, soot, etc. So up to $80 \%$ of benzene in the air is accumulated from emissions from vehicles [5].

The unfavorable ecological situation of territories with traffic areas saturated with motor transport leads to a significantly higher level of morbidity (up to 2 times) of the inhabitants of such territories, the oppression of plant resources and the reduction of bio-diversity.

The greatest negative impact of vehicles has when working with the engines in the modes "braking movement", which provides additional emission of harmful substances of the road surface and tire components when changing friction modes. Accordingly, it is necessary to ensure the uniformity of traffic units, reduce the volume and intensity of flows to reduce the burden on the environment.

B. Theoretical background of digital optimization of transport flows

The analysis of foreign and Russian publications allowed to reveal insufficient efficiency of constructive decisions in improvement of a road network and regulating influences on the organization of movement, in particular in the industrial and business centers with a high congestion of motor transport of various function that leads to deterioration of an ecological situation and quality of life of the population.

One of the directions of increasing the capacity of roads are economic measures with the introduction of toll on certain high-loaded sections. Another approach, forming the basis of this article, has a social and environmental orientation and is aimed at optimizing flows using computer-based measurement systems and satellite navigation.

Dynamic regulation of road load simultaneously contributes to the improvement of driving culture, as the reduction of obstacles in the lanes reduces the number of exits to oncoming lanes and lanes allocated for public transport.

Modern systems of photo and video recording should not only register events (flow density, average speed of movement, the presence of areas of downtime and obstructed traffic), but also transmit data to unified traffic control centers, where they are used to predict changes in the transport situation and the development of corrective actions.

In addition to photo-and video-fixation, other methods of detecting flows can be used, for example, by placing induction loops in the road surface, registering the number and mass of vehicles that have passed through the loop. Loops installed at the beginning and end of the traffic sections will allow you to determine the average speed and predict the probability of traffic jams when data is received in a single control system.

Similarly, infrared, ultrasonic, radar sensors placed on the side of the road or above it (on the lanes), will register the types and number of vehicles and their dynamics of movement, with the subsequent transmission of data to the control system. Also, GLONASS/GPS navigation systems can be used to receive and transmit traffic data and its coordination. Dynamically updated spatial models obtained from intelligent systems should also be integrated into a unified traffic management system and serve as a basis for flow modeling and digital transport management. services

C. Empirical model of digital optimization of transport

The main provisions of the model are as follows:

* Collection of information on the flow of vehicles. Recorded data: the type and number of units of transport in a particular area, the average speed, the presence of traffic accidents, the nature and intensity of traffic, etc. diagnostic Tools: photo, video recording, detectors of different nature placed above and under the roadway, satellite systems GLONASS / GPS.

* Transfer of collected information into a single traffic management system. Means of transmission: fiber-optic, wireless, satellite communication.

* Collection and transfer of additional information into a single management system affecting the functioning of the transport services sector. For example: weather data, environmental monitoring data, routes and timetables of public transport, maps of road networks, places of congestion of pedestrians, free Parking spaces, etc.

* Accumulation, storage and processing of data in the control system using software models of motion. In General, 2 main groups of models (1) macro - and (2) micro-level are recommended.

Models of type (1) consider the flow as a whole, with the analysis of its dynamics, which allows you to make constructive decisions on the construction of new road facilities and changing routes. Type (2) models consider units or groups of transport and serve to develop regulatory solutions for reverse flow optimisation.

- Optimizing the reverse impact on the functioning of the transportation sector. Means of transmission: fiber-optic, wireless, satellite communication. The types of regulatory impacts: coordinate the burning time of traffic light; data transfer on the scoreboard of public transport; transfer data on the display of the Parking lots; the placards with a range 
of routes of a detour of places that are difficult to movement; the transfer of data to the car navigation system (when connecting them to intelligent transport systems such as GLONASS/GPS); dynamic management of routes, etc.

\section{DISCUSSION}

Examples of individual design and regulatory solutions to improve the capacity of road networks are considered on the example of a number of Ye countries. Sun (2012), T. V. Bukina (2015), T. Thunig (2019), L. Kessler (2019), J. Żaka (2019), etc.however, there are no comprehensive works characterizing the features of flow control in megacities of Europe and Asia.

Some problems of registration of the composition and intensity of flows are solved in the works of V. V. Akulov (2012), A. A. Lobanov (2014), D. K. Bruno (2014), A.V. Belov (2017), E. A. Nurminsky (2014), M. M. Bekmagambetov (2012), etc.however, the publications reflect either the possibility of diagnostics, or the use of satellite systems, or mathematical modeling of flows, without a comprehensive display of the possibilities of digitalization in the field of transport services.

The novelty of this study is the theoretical justification of the possibilities of digitalization of transport services for dynamic traffic management, while improving the environmental situation in large cities. The proposed empirical model of digitalization of transport services sphere has practical value. it provides the possibility of integration of data from motion detectors and intelligent systems with subsequent modeling of flows and issuance of corrective actions.

\section{CONCLUSION}

The systematization of the world experience of traffic optimization is carried out and it is shown that the possibilities of constructive and regulatory solutions are insufficient for the provision of transport services just in time. Intensity of development of volumes of road transportations in RT and accompanying deterioration of an ecological situation is noted.

Possibilities of diagnostics of parameters of a stream with application of detectors and satellite systems are presented. The necessity of accumulation and processing of data on the movement in a single control center, where the use of mathematical modeling provides the issuance of corrective actions on the movement. An empirical model of digital optimization of transport services as a way to improve the environmental situation has been developed.

\section{References}

[1] L. p. Kurakov, V. L. Kurakov, A. L. Kurakov, "Economics and law: dictionary-reference", Moscow: University and school. 2004, 1071.

[2] Ye. Sun, "Research on Urban Road Traffic Congestion Charging Based on Sustainable Development”, Physics Proceedings. 2012, 24, pp. $1567-1572$.

[3] T. V. Bukina, E. K. Bukin, "Conceptual model of traffic organization in old industrial cities". In the book.: New models of intensive economic development: directions and prospects, Moscow: ECC "Professor". 2015, 5, pp.138-207.
[4] O. V. Mazurova, " Evaluation of comparative efficiency of use of automobile fuels and electric power for automobile transport", Economics of the region. 2019, vol. 15, 2, pp. 493-505.

[5] E. V. Bondarenko, G. P. Dvornikov, " Road transport ecology", Orenburg: OSU state University. 2004, 113.

[6] V. Popov, I. Yu. Miretsky, "Methodology of construction of logistics infrastructure in the region", Economics of the region. 2019, vol. 15, 2, pp. 483-492.

[7] L. V. Makarov, A. R. Bakhtizin, " Moscow traffic jams. Analysis and solutions", Budget. 2011, 2, pp. 16-20.

[8] Yu. V. Kopytova, " Methods of increasing road capacity", Young scientist. 2018, 5(191), pp. 196 - 197.

[9] D. K. Bruno, D. N. Bifulco, G. Fusco, et al, "its on road transport", Moscow: OOO "Typography Paradise". 2014, 532.

[10] A. S. Ponikarova. E. V. Bardakova, G. F. Tagirova., I. N. Ponikarova " Introduction of automated information management systems as a condition for achieving sustainable innovative development", Bulletin of Kazan technological University. 2012, vol. 15, 2, pp. 172-177.

[11] V. M. Starozhilets, Yu. V. Chekhov "," data Aggregation from heterogeneous sources in TP modeling problems", Machine learning and data analysis. 2016, 2, 3, pp. $260-275$.

[12] E. A. nurminsky, A. A. Fedoseev, V. S. Tormozov "Automatic determination of traffic flow density according to video surveillance cameras", Informatics and control systems. 2014, 1(39), pp. 151-159.

[13] V. V. Akulov, " Analysis of traffic intensity accounting methods on highways", Naukovedenie, 2012, 4, 7.

[14] Aleksandr S. Kuznetsov. Russian Professor' meeting. The Russian Journal of Physical Education and Sport. 2019, 14(1), pp. 17-22. DOI: 10.14526/2070-4798-2019-14-1-18-24.

[15] Program " Development and deployment of production forces of the Republic of Tatarstan... until 2030”, 2008, 356 p. 